\section{EL PENSAMIENTO CINEMATOGRÁFICO DE ROMAN JAKOBSON}

\author{
Alfonso Puyal \\ Departamento de Comunicación Audiovisual y Publicidad I \\ Facultad de Ciencias de la Información \\ Universidad Complutense de Madrid \\ Ciudad Universitaria \\ 28040 Madrid \\ puyal@ccinf.ucm.es
}

\section{ROMAN JAKOBSON'S CINEMATOGRAPHIC THINKING}

\begin{abstract}
The article turns on the film theory outlined by the Russian linguist from three contributions: the essay "Is the Film in Decline?" (1933); the interview on cinema realized in 1967; and some comments disseminated in its writings. The hypothesis that raises Roman Jakobson is the transposition of the literary features to the cinematographic mean, until rising what the Russian formalists came in calling "Poetics of Cinema" (Poetika Kino). In this sense, the most revealing contribution is the study of the metonimic and metaphorical functions that the cinema unfolds from the segmentation and the assemblage. A panoramic one by the relations that maintained Jakobson with the poets and painters of the Czech and Russian avant-garde, their culture in film matter (movies, filmmakers), or the theoretical references that handled in film questions are some of the themes undertaken with the aim to contextualize the vision that Jakobson had of cinematographic medium. The thickness of the article will be centered in its article of 1933 on movies, writing as a result of the consequences of the sound in the film language, as well as of a small experience in the making of the movies during its stay in the Czech Republic.
\end{abstract}

KEY WORDS: Roman Jakobson; film theory; linguistics; poetics; avant-garde.

La importancia que otorgó el lingüista ruso Roman Jakobson a las artes visuales, en tanto que sistema de signos equiparable al arte verbal o al lenguaje mismo, hizo que a lo largo de su carrera intelectual estableciera todo un nudo de transposiciones de un sistema de signos a otro; un ejercicio de constante búsqueda tanto de las invariantes como de los rasgos distintivos que caracterizan
RESUMEN: El artículo versa sobre la teoría cinematográfica esbozada por el lingüista ruso a partir de tres aportaciones: el ensayo "¿Decadencia del cine?" (1933); la entrevista sobre cine realizada en 1967; y algunos comentarios diseminados en sus escritos. La hipótesis que plantea Jakobson es la transposición de los recursos literarios al medio cinematográfico, hasta levantar lo que los formalistas denominaron "poética del cine" (Poetika kino). En este sentido, la aportación más reveladora es el estudio de las funciones metonímicas y metafóricas que el cine despliega a partir de la planificación y el montaje. Una panorámica por las relaciones que mantuvo Jakobson con los poetas y pintores de la vanguardia rusa y checa, su cultura en materia cinematográfica (películas, cineastas), o las referencias teóricas que manejó en materia fílmica son algunos de los temas abordados con el fin contextualizar la visión que Jakobson tenía del medio cinematográfico. El grueso del artículo estará centrado en su artículo de 1933 sobre cine, escrito a raíz de las consecuencias del sonido en el lenguaje cinematográfico, asi como de una pequeña experiencia en el oficio del cine durante su estancia en la república checa.

PALABRAS CLAVE: Roman Jakobson; teoría cinematográfica; lingüistica; poética; vanguardia.

En arte, fue el cine el que reveló clara y enfáticamente que el lenguaje era sólo uno de los posibles sistemas de signos.

(Roman Jakobson, “¿ué es la poesía?", 1934)

a cada medio de expresión. El origen de esa búsqueda puede rastrearse en sus años de juventud, así como en la relación personal que mantenía con artistas y escritores de la incipiente Unión Soviética. Por entonces, el cubismo y el futurismo -con sus derivaciones literarias- son los movimientos que de manera más profunda calan en la primera vanguardia rusa. 
Dos van a ser los focos de interés artístico de Jakobson: la pintura abstracta (signo pictórico) y el lenguaje supraconsciente (signo verbal). El nexo común será el estudio de la forma pictórica o la palabra en sí misma, desprovistas ambas de su función representacional. "Por mi parte, yo me esforzaba obstinadamente en mis textos y en mis meditaciones teóricas en alejarme de las palabras y de su significación, en concentrarme en los componentes elementales de la palabra, en los sonidos del lenguaje en cuanto tales" (Jakobson, 1981, 17). Su trabajo teórico va a ir acompañado de la creación poética a través de la composición de versos transrracionales (zaum), ilustrados por artistas como Olga Rozanova.

Esa inquietud por la experimentación formal en arte queda reflejada en varios artículos, publicados entre 1919 y 1921, dedicados a diferentes manifestaciones de la vanguardia. Precisamente su curiosidad por el dadaísmo le remite al Almanaque dadá (1920), editado por Richard Huelsenbeck $y$, de ahí, al cine: "El teatro se muere, la película está en ciernes. La pantalla deja poco a poco de ser el equivalente de la escena; ella misma se libera de las unidades teatrales, de la mise en scène teatral" (Jakobson, 1987, 39). La reflexión no es sino la respuesta a la eclosión del medio cinematográfico y al lugar que ocupa con respecto al teatro. Por esos años el cine se plantea como un nuevo medio de expresión que se debate entre el mantenimiento de las formas dramáticas y la construcción de un lenguaje propio.

En el ensayo titulado "Futurismo" (1919), se lee: "La eliminación del estatismo, la expulsión de lo absoluto: he aquí la tendencia esencial de los tiempos modernos" (Jakobson, 1987, 30). Y es en esa irrupción de lo dinámico donde entra en acción el dispositivo cinematográfico; un mecanismo que por otra parte se vale de imágenes estáticas (fotogramas) y que, una vez proyectadas, dan la impresión de percibir un movimiento continuo. Esta cuestión nos lleva al estudio diacrónico y sincrónico del lenguaje, planteado por Saussure y cuestionado por Jakobson. Ante la identificación de la diacronía con un proceso dinámico y la sincronía entendida como una prospección estática, Jakobson argumenta:

"Al criticar esta concepción, recurri al ejemplo de la percepción cinematográfica. A la pregunta de tipo sincrónico: ¿qué ve usted en este mismo instante sobre la pantalla del cine?, el espectador dará inmediatamente una respuesta de orden sincrónico, y no estático, ya que en este momento ve correr a los caballos, dar volteretas al payaso, caer bajo las balas del bandido. En definitiva, estas dos oposiciones efectivas, sincronía-diacronía y estática-dinámica, no coinciden en la realidad" (Jakobson, 1981, 63).

\section{LA VANGUARDIA CHECA}

Entre 1920 y 1939 Jakobson se expatria a Checoslovaquia. Alli entrará en contacto con la amplia actividad pictórica, poética y literaria propiciada por la vanguardia; especialmente a través de la relación trabada con el polifacético Karel Teige, el poeta Vítězslav Nezval o el prosista Vladislav Vančura. En esos años Jakobson colabora con artículos sobre arte, poesía o filología en revistas muy sintonizadas con la vanguardia internacional (Červen, Pásmo, Život). La práctica artística y crítica conectará así con los estudios de la Escuela Lingüística de Praga y con el naciente método estructural.

Karel Teige, figura visible de la vanguardia checa, se ocupó del cine junto a temas de arte moderno, diseño gráfico o poesía visual, en tanto que síntomas de la modernidad y la mecanización del arte. Igualmente fue uno de los fundadores de la unión artística Devitsil, grupo cercano al constructivismo y del que Jakobson formó parte. En medio de esa intrincada red de relaciones entre artistas y académicos, surge la noción de poetismo; noción que es mencionada por Jakobson en "¿Qué es la poesía?" (1934): "La poeticidad se presenta cuando la palabra es sentida como palabra y no como mera representación del objeto nombrado o una explosión emotiva, cuando las palabras y su composición, su significado, su forma externa e interna adquieren un peso y valor propios en vez de referirse indiferentemente a la realidad" (Jakobson, 1987, 378). En términos cinematográficos, la modalidad más radical de "la palabra como tal" encontraría su equivalente en el cine experimental (cine puro, absoluto, integral o abstracto), al que se volverá en el último epígrafe.

Los miembros y los escritos de Devětsil bien podían proveer de ideas a Jakobson con vistas a escribir sobre cine. Vančura había escrito guiones para películas experimentales y terminará dirigiendo largometrajes de ficción, mien- 
tras que Teige había publicado en 1925 una colección de artículos reunidos bajo el título Film, muy permeable a las ideas estéticas del momento. El poetismo quería ofrecer al espectador poemas cinematográficos: "Estas películas tendrian entonces, sin dejar de ser abstractas en su núcleo, elementos naturalistas que se forman dentro de un sistema de composición abstracta" (Teige, 2002, 83). Por su parte, Jan Mukǎrovský, perteneciente al Círculo Lingüístico de Praga, escribió "En torno a la estética del cine", texto que analiza diferentes recursos filmicos, como son el "cambio de toma" (planificación), el "detalle" (primer plano), o la "localización del sonido fuera de la imagen", aspecto este último que sugerirá la "sensación del espacio entre la imagen y el sonido" (Mukařovský, 1977, 216).

Será en ese caldo de cultivo donde Jakobson no sólo escribirá sobre cine, sino también se familiarizará con el rodaje de películas por mediación de Vladislav Vančura, para el que escribe el guión de En el lado soleado ( $\mathrm{Na}$ sluneční straně, 1933). Asimismo, Jakobson mencionará en su ensayo sobre cine el primer largometraje codirigido por Vančura, Pred maturitou (Antes de la graduación, 1932), y pondrá de ejemplo una escena de la película para resaltar el valor expresivo del silencio en el cine sonoro.

\section{¿DECADENCIA DEL CINE?}

La incorporación del cine a las formas artísticas, encaminadas a esa eliminación de lo estático de la que hablaba Jakobson, se corresponde con el enorme interés que los sectores renovadores de la intelectualidad y las artes profesan hacia la expresión cinematográfica. No hay más que leer al párrafo inicial del único texto que Jakobson escribiera sobre cine: "Asistimos al nacimiento de un arte nuevo (...) Se aparta de la influencia de las artes más antiguas, empieza incluso a ejercer una acción sobre ellas" (Jakobson, 1976b, 173)'.

Jakobson cuenta el origen de este ensayo, escrito en checo y publicado en 1933 por una revista cultural editada en Praga ${ }^{2}$. Paradójicamente titulado "¿Decadencia en el cine?", el artículo surge de los problemas suscitados por la implantación del sonido en las películas; un cine sonoro del que el lingüista es ferviente partidario: "Ciertos teóricos han colocado con demasiada rapidez la mudez en el con- junto de las propiedades estructurales del cine, y se sienten ofendidos si el desarrollo ulterior de éste se aparta de sus formas" (176). La controversia levantada por cineastas y teóricos en torno a la irrupción del cine sonoro desató todo un debate del que se hicieron eco diarios, revistas y libros especializados. Algunos críticos veían en el sonoro, y sobre todo en los diálogos, un retroceso en relación a los recursos hasta entonces alcanzados por el lenguaje del cine mudo.

Émile Vuillermoz, esteta y musicólogo francés, se ocupó de resaltar el carácter eminentemente musical del filme mudo. En "Música de las imágenes" escribia Vuillermoz: "Se ha cometido un error al llamar al cine arte mudo; es en realidad arte silencioso. No conviertan en imperfección lo que es una fuerza oculta" (Vuillermoz, 1927, 52). Jakobson contesta a Vuillermoz a tenor de una cita sobre el diálogo, que reproduce en su ensayo sobre cine: "La manera compulsiva e irregular en que se traduce la palabra a ratos, en un arte anteriormente silencioso, y en que se la aparta a ratos, destruye la ley del juego y subraya el carácter arbitrario de los intervalos de silencio" (Moussinac, 1967, 247). Vuillermoz se refiere a la época en que las partes dialogadas irrumpian en un montaje propio de un "arte mudo" que todavía no se había adaptado a la banda sonora. Jakobson, por su parte, ve en esas zonas de silencio -a veces arropadas por segmentos musicales- una fuerza dramática que los puristas no terminaban de distinguir.

Para Rudolf Arnheim, teórico que inicialmente se opuso al empleo de la película hablada en El cine como arte (1932), la potencialidad creativa del cine estaba basada, precisamente, en las limitaciones del medio en relación a la realidad física. Ello se traducia en los límites del encuadre, el tamaño de la imagen, la fotografía en blanco y negro o la ausencia de sonido. Es este último aspecto al que Jakobson responde: "El silencio en el cine tiene el valor de una verdadera ausencia de ruido (...) En un filme sonoro, percibimos el silencio como un signo de silencio real" (177-78). Un escrito fundamental que enriqueció el debate fue la declaración de 1928 sobre el sonido, debida al director soviético Sergei M. Eisenstein y suscrita por Vsevolod I. Pudovkin y Grigori V. Alexandrov. Ellos demandaban que el "sonido debe ser encaminado hacia su no sincronización distintiva con las imágenes visuales" (Eisenstein, 1986, 236). Se trataría por tanto de alcanzar una relación de "contrapunto" entre el segmento sonoro 
y la imagen icónica. Este planteamiento coincide plenamente con la tesis de Jakobson, al tratar las relaciones contrapuntisticas: "En un film sonoro, la realidad óptica y la realidad acústica pueden ser presentadas juntas 0 , por el contrario, estar separadas: se puede mostrar la realidad óptica sin el ruido que normalmente va unido a ella, o bien separar el sonido de lo óptico (...) Se ofrecen pues a la sinécdoque cinematográfica nuevas posibilidades" (178). Lo que defiende Jakobson es que el sonido sea utilizado como elemento de montaje, de igual manera que se monta el material filmado.

\section{LOS POLOS METAFÓRICO Y METONÍMICO}

Entre los temas que ocuparon al lingüista se encuentra el funcionamiento de la metáfora y la metonimia, entendidos éstos como factores que operan en cualquier nivel de lenguaje:

"El primero de estos factores, la selección, se produce sobre la base de la equivalencia, de la similaridad y de la disimilaridad (...) mientras que en el segundo, la combinación, la construcción de toda cadena reposa sobre la contigüidad: si se estudia el papel de estos dos factores en el lenguaje poético, queda claro que la función poética proyecta el principio de equivalencia del eje de la selección al eje de la combinación. La equivalencia queda promovida al rango de procedimiento constitutivo de la secuencia" (Jakobson, 1976a, 105).

A partir de la función bipolar que todo sistema de signos lleva implícito; a partir de las oscilaciones que se producen del eje de la selección al eje de la combinación, ¿de qué manera traspone el lingüista este planteamiento al lenguaje del cine? Para Jakobson el cine trabaja "con fracciones de espacio y de tiempo de dimensiones diferentes; modifica las proporciones de estas fracciones y las confronta según su proximidad, o según su parecido o su oposición, es decir, que toma prestada la vía de la metonimia o de la metáfora" (175). Pero a este valor predominante, que es el eje de la combinación, se añaden las asociaciones metafóricas. El fundido encadenado o la sobreimpresión van a servir efectivamente de recurso para establecer asociaciones entre elementos que no tienen porqué poseer proximidad o coherencia argumental. Ahí se establece la eficacia expresiva de la metáfora: asociaciones -por analogía o contraste- que se encadenan mediante fundidos. Las asociaciones generadas por la planificación y el montaje a veces pueden ser presentadas por contraste; un contraste motivado tanto por aspectos compositivos (formas enfrentadas) como temáticos (conceptos opuestos).

Hablar de este tipo de montaje contrastado lleva irremisiblemente a Eisenstein a reclamar para el cine un montaje de enfrentamiento, de choque entre imágenes. El montaje dialéctico sirve para expresar ideas mediante la colisión de motivos independientes, incluso contrarios: "El montaje es una idea que surge del choque de las tomas independientes -tomas incluso opuestas una a otra: el principio 'dramático'" (Eisenstein, 1986, 51). En la entrevista, tras incluir a Eisenstein en la casuística del filme metafórico, llama la atención sobre sus escritos cinematográficos. En ellos "se encuentran ideas, pasajes que muestran cómo Eisenstein no fue sólo un creador genial en el campo del cine, sino también un gran especialista, un teórico y un historiador del cine y el arte" (Jakobson, 1967, 158). Jakobson indirectamente menciona el estudio comparativo "Dickens, Griffith y el cine en la actualidad" (1944); especialmente le llama la atención la importancia que Eisenstein atribuye al monólogo interior de Joyce, y que pone en relación con su idea del montaje intelectual.

\section{CULtura filmica}

Habria que preguntarse cuáles son las fuentes con las que contaba Jakobson a la hora de abordar el fenómeno del cine desde el enfoque lingüistico y también semiótico. Hay dos vertientes a las que el lingüista acude a lo largo del artículo: de un lado, el formalismo ruso emprendido por los estudios literarios, junto a los directores soviéticos que abordan la reflexión teórica; de otro, los cineastas y teóricos de la escuela impresionista francesa, formados en la literatura y en revistas programáticas como L'Esprit Nouveau (1920-1925). Hay también referencias a Béla Balázs, escritor húngaro que desarrolló su trabajo en Alemania. En Viena Balázs publicó un pequeño volumen fundacional en lo que a teoría fílmica se refiere: El hombre visible o la cultura del cine (1924). Una de las cuestiones planteadas en El hombre visible -la finalidad del acompañamiento musical en las películas mudas-, está recogida 
por Jakobson en su relación de citas: "[N]os damos cuenta inmediatamente de la ausencia de música, pero no prestamos ninguna atención a su presencia, lo que supone que cualquier música conviene de hecho a cualquier escena" (Balázs, 1926, 143).

En cuanto a la escuela francesa, sus representantes van a desarrollar un importante cuerpo teórico. No olvidemos que algunos de ellos (Ricciotto Canudo, Louis Delluc, Jean Epstein) van a acercarse al cine a través de la literatura, y que la mayoría (Abel Gance, Marcel L'Herbier, Germaine Dullac) va a formalizar por escrito los resultados de su práctica filmica. También llamada vanguardia narrativa, se trata de un cine de argumento, aunque con una estilización visual -"deformaciones plásticas" dirá Moussinac- que lo alejará del verismo. Los cineastas intentarán componer mediante el montaje rítmico de imágenes -ya sea por sucesión como por superposición- un trasunto de los recursos poéticos.

A lo largo del artículo se hace sentir la presencia de la escuela francesa, tanto de directores como de teorizadores y críticos. En lo que se refiere a la función de la música en el cine mudo figuran Émile Vuillermoz, Paul Ramain y Frank Martin. "La música del filme está destinada a no ser escuchada" (178) es una sentencia tomada por Jakobson del doctor Paul Ramain, psicólogo que indagará en las relaciones del cine con los sueños y la música: "Car la musique au Cinéma devra rester le bruit préconisé par [Arthur] Honegger, la rumeur ronronnante préconisé par nous et destinée à ne pas être écoutée, mais à créer le silence dans la salle" (Ramain, 1925, 126). Otro tanto hará el músico suizo Frank Martin, del que Jakobson entresaca una curiosa apreciación. La música de foso en la sala de cine -señala el músico- desempeña un papel secundario: "su única finalidad es ocupar los oídos mientras que toda la atención se concentra sobre la vista"3. Con todo lo visto, Jakobson zanja la cuestión otorgando a la música una "función neutralizadora", de tal manera que -afirma- "no es el silencio, sino la música, lo que significa en el cine la exclusión de lo acústico" (180).

En lo referente a los "principios verbales y sustantivos del cine", mencionados de pasada en el artículo (174), Jakobson alude al escritor André Beucler, un autor que tendrá experiencias no sólo como guionista sino también como director cinematográfico durante la década de los treinta. El artículo lleva un oportuno título, "El poema cinematográfico", y en él puede leerse: "Le film est verbe ou substantif. Je propose des SIGNES que s'addressent d'abord à l'attente des yeux puis, avant de se déposer sur le fond de la raison, aux mille vertiges intermédiaires qui imitent si parfaitement, dans l'association des idées, ce spectacle sans déchirures mais sans logique qui est le monde visible" (Beucler, 1925, 134-35). Del mismo modo que, a grandes rasgos, en el lenguaje verbal o escrito la acción corresponde al verbo y la descripción al sustantivo, el lenguaje del cine parece que pide planos generales para la acción -mayor dinamismo- y planos más cercanos para las escenas descriptivas -mayor estatismo-, en donde la imagen se detiene en los objetos.

De Louis Delluc el lingüista hará referencia al ensayo de 1920 Photogénie. Este neologismo, utilizado por vez primera por Canudo, lo aplica Delluc para definir la revalorización de los rostros, los objetos o los paisajes por el hecho de ser tomados por una cámara cinematográfica. Para ello, la escuela francesa recurrirá a una serie de efectos técnicos como puedan ser los valores de la fotografía en blanco y negro, el flou (desvanecido), el contraluz, el ralentí. El tratamiento fotográfico de la luz será por tanto un recurso clave para lograr cierto grado de poeticidad. Pues bien, dichos efectos no son sino los "tropos cinematográficos" de los que habla Jakobson (1976a, 110). La planificación cinematográfica interviene sobre la escena fragmentándola, ya esté formada por objetos inanimados o por seres vivientes -"rostros, máscaras", dirá Delluc-. El actor, esa instancia que encarna a un personaje, no es para Delluc más que "un detalle, una migaja de la matière du monde"t. La cita viene a colación por la duda que Jakobson plantea en torno a cuál es la materia que transforma el arte del cine; si son los elementos de la escena (objetos, decorados) o el material filmado (imágenes visuales y acústicas). Jakobson contesta taxativamente que la potencia expresiva del cine se encuentra en la representación, no en la escena, dado que "cada fenómeno del mundo exterior se transforma sobre la pantalla en signo" (175).

La autonomía del cine con respecto al teatro abrirá todo un debate en la escuela francesa. Junto a otros cineastas, Jean Epstein reclamaba para el cine su emancipación del teatro, en tanto que lenguaje universal de imágenes en movimiento. Aunque Jakobson no se apoya en citas específicas, una nota a pie de página remite a la obra Bonjour

ARBOR Vol. 187748 marzo-abril [2011] 411-420 ISSN: 0210-1963

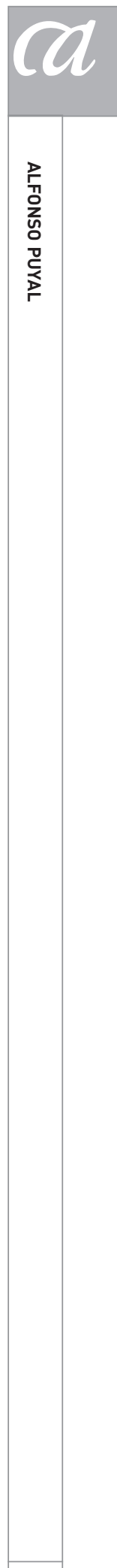

415 
cinéma, en la cual se encuentran algunos pasajes relativos al teatro filmado ${ }^{5}$. Refiriéndose a la querella entre el cine y el teatro, Jakobson concluye: "Hay quien afirma que el filme sonoro ha acercado peligrosamente el cine al teatro. Es verdad, lo ha acercado de nuevo (...) para acelerar el advenimiento de una nueva liberación" (176-77).

\section{Poetika kino}

El segundo cimiento teórico sobre el cual Jakobson va a sentar su pensamiento cinematográfico será la vertiente cinematográfica de los formalistas soviéticos, habida cuenta de que él era uno de sus máximos exponentes y de que, por entonces, se sucedian los debates sobre cine en función del lenguaje, la narrativa o la poesía. "Me acuerdo de ciertas discusiones muy vivas (...) en el Círculo Lingüístico de Moscú, en 1919, sobre la cuestión de saber si el cine es o no arte; me acuerdo que éramos sobretodo [Viktor] Sklovsky y yo quienes estábamos en la idea de que sí, al mismo tiempo Osip Brik (...) estaba en el lado contrario" (Jakobson, 1967, 161). En efecto, en una lista de las conferencias elaborada por Grigori 0. Vinokur figura una de Sklovski sobre la "Composición del sujet en el arte cinematográfico" (Toman, 1995, 62). Especialmente rotundas son las sentencias vertidas por Sklovski en "Literatura y cine" (1923): "La poética del cine es la poética del puro 'argumento' [siuzhet], connatural al propio carácter de la toma cinematográfica" (Sklovski, 1971, 50); es decir, que la poética cinematográfica reside en la preponderancia de los recursos técnico-formales sobre los elementos semánticos o temáticos ${ }^{6}$.

En pleno fervor futurista -es la época en que Vinokur afirma que los futuristas son "constructores del lenguaje"-, surge en 1916 un círculo afín, la Sociedad para el Estudio del Lenguaje Poético (OPOYAz), alguno de cuyos miembros colaborará en el volumen colectivo Poetika kino, publicado en Leningrado en 1927. Es Boris Eikhenbaum quien coordina la edición de Poética del cine y quien abre el volumen con "Problemas de cine-estilística". Sobre aquel volumen, fundamental en lo que afecta al desarrollo de posteriores teorías cinematográficas, recuerda Jakobson lo siguiente:

"Yo los leía cuando aparecieron pero después no los he vuelto a leer. No me acuerdo nada más que del de [Boris]
Kazanski; no tenía nada en contra. Recuerdo sin embargo el impacto que me había causado Eikhenbaum y Tynianov, aunque tenía alguna objeción que hacer al primero; pero no me acuerdo de más detalles. Sin embargo, en general, los artículos de Sklovsky sobre el cine no me gustan, los encuentro muy superficiales. No me acuerdo de otros textos" (Jakobson, 1967, 161).

En su ensayo Jakobson se detiene en el método formal cuando advierte que "los estudios sobre el cine hablan sin cesar metafóricamente de la lengua y hasta de la frase cinematográfica con un sujeto y un atributo (B. Eikhenbaum)" (174). En efecto, esa inclinación, un tanto mecanicista, consistente en trasladar las reglas del lenguaje a la imagen en movimiento, se advierte sensiblemente en el artículo de Eikhenbaum: el cine procede por una suerte de fraseología; incluso se refiere al cambio de angulación de una misma escena como una "especie de proposición subordinada". A partir de ahí, sostiene la existencia de la cine-sintaxis, articulada a través del montaje; o de la cinemetáfora, que no deja de apoyarse en el segmento verbal: "La cine-metáfora es una especie de realización visual de una imagen verbal (...) La metáfora cinematográfica es, por decirlo así, la auténtica plasmación en la pantalla de una metáfora verbal" (Albèra, 1998, 66 y 74).

Más adelante Jakobson hará lo propio con Yuri Tynianov al recurrir de nuevo a Poetika kino y a "Los fundamentos del cine", para destacar que su "análisis del movimiento y del tiempo cinematográfico" evidencia "que cada fenómeno del mundo exterior se transforma sobre la pantalla en signo" (175). Según Tynianov, el arte del cine no radica en la toma de imágenes en movimiento, en su fotogenia -"los objetos no son fotogénicos en sí mismos"-, sino en la "transfiguración estilística" Ilevada a cabo a partir de unos recursos que no siempre deben buscar la reproducción mecánica de la realidad ni tener una motivación naturalista. Los procedimientos estilisticos del cine van adquiriendo así un carácter autónomo e intrínseco que lo aleja de la verosimilitud con lo real o de motivaciones literarias. "En el cine, el mundo visible no es ofrecido como tal, sino en su correlación semántica, de otro modo el cine no sería más que fotografía animada (o muerta). El hombre visible, la cosa visible, sólo son el elemento del arte cinematográfico cuando son ofrecidos en calidad de signo semántico" (Albèra, 1998, 83). 
Cercano a la órbita formalista está otro estudioso que más tarde se dedicará a la realización de películas, Semion Timoshenko, quien publica en 1926 el "primer ensayo en el terreno de la teoría y estética del montaje", titulado El arte cinematográfico y el montaje del filme: ensayo de introducción a la teoría y la estética del cine ${ }^{7}$. Timoshenko sigue la creencia de que el montaje no es sino la "organización del material cinematográfico" (Pudovkin, 1956, 208); que éste debe regirse por la gestión científica del trabajo (Taylorismo); y que el cineasta debe constituirse en un ingeniero, al igual que proclamaban los artistas constructivistas. A partir de estas premisas, propone la enumeración de quince métodos de montaje. En alguno de los ejemplos apunta distintos usos de los letreros. Básicamente resalta el empleo de los títulos explicativos para indicar el paso del tiempo o los cambios de lugar. A la hora de valorar la función de los intertítulos, Jakobson menciona el opúsculo de Timoshenko y añade: "Los letreros intercalados eran, en los filmes mudos, importantes medios de montaje; funcionaban a menudo como un enlace entre las escenas (...) Se encontraban pues en el filme unos principios de composición puramente literaria. Por eso se intentó librar al filme de sus letreros, pero estas tentativas acarreaban, ya una simplificación del tema, ya una disminución del ritmo" (179). La llegada del sonoro supuso cierta liberación del lastre literario que imponian los intertítulos, al tiempo que amenazaba un nuevo peligro, la teatralización del filme a la que aludian tantos críticos.

\section{El caso Maiakovski}

Vladimir Maiakovski y Jakobson comenzaron a entablar relación en los años futuristas; fue hacia 1914, cuando se produjo la visita de Marinetti a Moscú. Antes habían coincidido en las encendidas reuniones mantenidas en 1912 con Sota de Diamantes, un grupo se pintores prerrevolucionarios que avanzaban la abstracción, y después en las intervenciones de Maiakovski ante el círculo lingüístico de Moscú. Fue también Maiakovski quien participó en la efervescencia del futurismo anterior a la revolución soviética, y del que Jakobson fue testigo directo: "Entonces veía muchas películas. Recuerdo que vi el primer filme futurista ruso, Drama v kabare futuristov n. ${ }^{\circ} 13$, con Larionov y Goncharova" (Jakobson, 1967, 161). Los versos de Maiakovski "Para vosotros el cine es espectáculo / Para mí casi una visión del mundo", pertenecientes al poema "Cine y cine", reflejan el lugar del nuevo medio en la creación literaria. El interés del poeta por las posibilidades que ofrecía el cine tuvo no pocas derivaciones: la redacción de tempranos artículos sobre cine; su participación en la primera política cinematográfica tras la revolución soviética; la escritura de guiones, algunos de los cuales se llevaron a la pantalla, aunque con escasa satisfacción por parte de su autor; o la faceta de actor en películas, tres de ellas escritas por él para la productora Neptuno.

"Sobre cine existen numerosos escritos interesantes en el primer volumen de las obras de Maiakovski, cosas muy curiosas desde el punto de vista histórico", comenta Jakobson (1967, 161). Efectivamente, entre julio y septiembre de 1913 Maiakovski entrega tres colaboraciones a la revista Kine-Journal; artículos centrados principalmente en las implicaciones entre cine y teatro. Es notoria aún la precaución ante el cine considerado como hecho artístico: "¿Puede el cine ser una forma artística independiente? Obviamente, no (...) Sólo el artista evoca las imágenes artísticas de la vida real, mientras que el cine puede ser tanto un exitoso como fracasado multiplicador de sus imágenes (...) Cine y arte son fenómenos de diferente orden" (Taylor y Christie, 1988, 36). A tenor de la posterior actividad cinematográfica de Maiakovski, dicho estado de opinión variará considerablemente un lustro después, aunque su relación quedara frustrada por las imposiciones de la cinematografía primero privada y después estatal.

\section{EL EXPERIMENTO KULESHOV}

Un director con el que Jakobson compartirá estrechamente su línea de pensamiento es Lev Kuleshov, cineasta que si bien no destacó en la práctica fílmica, sí lo hizo en la teoría y la enseñanza cinematográficas; así hasta convertirse en el verdadero mentor de la cinematografía soviética a partir de sus ideas y experiencias sobre montaje. No en vano, a partir de 1923 Kuleshov se escinde de la escuela estatal de cinematografía y forma un taller de cine que también es conocido como "laboratorio experimental".

En la entrevista para Cinema e Film Jakobson se refiere a la faceta teórica de director, que "habla precisamente de los elementos últimos o de las unidades últimas del cine y 
desarrolla así una teoría binaria de los gestos como signos que se oponen. Él analiza de inmediato diferentes tipos de dicotomías" (Jakobson, 1967, 161). Una de las vertientes que más intensamente trabajó el taller Kuleshov fue la interpretación, y de ahí surge la "teoría binaria de los gestos" a la que se refiere Jakobson, que consiste en el establecimiento de un repertorio de acciones basadas en situaciones contrarias.

A la interpretación de los actores modelos -"tipos" es otra acepción- se sumaba la intervención del montaje. Así, los efectos del montaje conseguian dar un sentido $u$ otro a la escena en virtud del orden o la duración de los planos. Dicha articulación lograba alcanzar las mismas cotas expresivas que el texto literario, de modo que no es de extrañar que tanto los formalistas soviéticos como el mismo Kuleshov hablasen de sintaxis filmica.

En "¿Decadencia en el cine?" Jakobson plantea la obra de Kuleshov en términos semióticos: "Kuleshov (...) dice con razón que el material cinematográfico está constituido por las cosas reales (...) Pero por otra parte, la materia de todo arte es el signo, y los cineastas son conscientes de la esencia semiológica de los principios cinematográficos" (174). A renglón seguido el lingüista cita la sentencia de Kuleshov "Un plano debe actuar como un signo, como una letra [del alfabeto]" (Kuleshov, 1974, 62), frase perteneciente a EI arte del cine (1929), primer libro de teoría cinematográfica escrito por el cineasta. Kuleshov plantea en este ensayo la disyuntiva entre el cine que surge de los acontecimientos filmados, sean reales o ficticios (tendencia realista), y la postura opuesta, es decir, la expresión cinematográfica que nace del tratamiento del material filmado (tendencia formalista). En suma, se trataría de discernir si el material procede de la escena filmada o de los fragmentos de película. El director soviético se inclina claramente por lo segundo, y es taxativo al respecto:

"Si se tiene una idea-frase, un fragmento de historia, un eslabón en la cadena dramática completa, entonces esa idea está expresada a base de planos-signo, como ladrillos (...) [El director] no debería concebir primero el contenido del episodio y luego tratar el material visual para devolverlo a la pantalla. La concepción de un episodio y la elaboración del mismo deberían brotar de las imágenes, del material que se haya filmado. Además, los distintos cortes y una distinta construcción -el montaje de los encuadres- pue- den cambiar la concepción de todo un episodio" (Kuleshov, 1974, 91 y 92).

Se deduce de estas líneas algo que subyace en el pensamiento de Jakobson: el montaje cinematográfico opera con la contigüidad espacial y la continuidad temporal; es decir, prevalecen las asociaciones metonímicas entre planos 0 secuencias. Es cierto que la fragmentación, el detalle y los planos insertados rompen con la linealidad espacial -está el experimento de la "geografía creada" en el que un espacio fragmentario se recompone a través del montaje-; es cierto también que con las elipsis determinados segmentos temporales se contraen e incluso se eliminan. Pero los recursos del montaje empleados por el cine -incluidas las experimentaciones del período mudo- tienden a una integración que, si no narrativa, termina por dar coherencia al texto; coherencia tanto temática como discursiva. De este modo, se organiza toda una dialéctica entre la entidad autónoma de los planos -como "letras del alfabeto"; igual que "ladrillos"- y la cohesión entre las partes del conjunto, de la cadena sintagmática. De ahí la conclusión de Jakobson referida a los cruces entre metáfora y metonimia: "Todo elemento secuencial es símil. En poesía, en la que la similaridad se sobrepone a la contigüidad, cualquier metonimia es ligeramente metafórica y toda metáfora tiene una tonalidad metonímica" (Jakobson, 1975, 382). Los soviéticos no dejarán de hablar de montaje, de fragmentos o elementos heteróclitos, pero finalmente el tratamiento poético de un texto filmico acaba por alcanzar un sentido pleno y clausurado. Eisenstein así lo expuso al escribir sobre montaje: "En todos los casos, su rasgo fundamental y definidor era su capacidad de combinarse y unirse en un todo; y si la totalidad se dividía en fragmentos, era no sólo para juntarse simplemente después, sino para ensamblarse de nuevo en un todo más perfecto imaginado por la mente humana, un todo nuevo, transformado, ejemplar" (Eisenstein, 2001, 231).

\section{El LUGAR DEL CINE ABSTRACTO}

De la misma manera que la pintura y la poesía tomaron el camino de la abstracción, el cine se planteó el juego de imágenes en movimiento mediante el empleo de la luz, la forma o el color. Esta vía experimental, más allá de las modalidades narrativa y documental, fue tomada princi- 
palmente por pintores que querian extender su trabajo al medio cinematográfico. En muchos aspectos coincidía con la búsqueda del ritmo cinemático -analogías musicales-, así como la transformación de figuras -analogías poéticas-. En esta búsqueda entran en juego las metáforas visuales, de tal manera que las asociaciones entre objetos no proceden tanto de un valor simbólico, sino meramente formal.

Kazimir Malevich, de quien Jakobson tomó prestadas sus ideas sobre la distribución de las "masas de letras-sonidos" en relación con la pintura suprematista, era un verdadero partidario del cine "sin objeto", y en 1927 emprendió con Hans Richter un proyecto inacabado con el título Una película artística y científica. A Malevich lo que le interesa es "el tema del cine-form como tal, como algo inherente a la naturaleza o a la peculiaridad del cine", como propone en el artículo de 1929 "Leyes pictóricas en los problemas cinematográficos" (Tupitsyn, 2002, 148).

No obstante, y con todo lo dicho, Jakobson sentía prevención hacia el cine abstracto: "[P]ermítanme hacerles compartir mi experiencia personal de las películas abstractas. Aunque habiendo pertenecido a los partidarios ardientes y activos de la pintura abstracta desde sus primeros pasos en Rusia (...) me siento totalmente agotado después de haber mirado esa clase de películas durante cinco o diez minutos, y he reunido numerosos testimonios semejantes en otras personas" (Jakobson, 1976a, 116). Por consiguiente, los procesos de abstracción que tan enriquecedores habian sido para la poesía y la plástica, quedaban invalidados en la práctica cinematográfica.

\section{CodA}

Jakobson señala en varios lugares que el proyecto semiótico en torno al cine es un asunto pendiente. Así, en su estudio sobre los trastornos afásicos del lenguaje anota que había trabajado sobre los "giros metonímicos" en el arte verbal, en la pintura y en el cine, pero que "la cuestión crucial de los dos aspectos polares [metáfora y metonimia] se halla todavía pendiente de investigación detallada" (Jakobson, 1973, 129n). De igual modo, y refiriéndose a su artículo de 1933, admite: "También creo haber escrito, en una nota del texto, que debía ser para mí como un adelanto de un trabajo más amplio sobre la semántica del cine, que yo no realicé porque fui llamado por la universidad y me tuve que ocupar en problemas de filología" (Jakobson, 1967, 162).

En cualquier caso, la tendencia que siguieron sus reflexiones sobre cine, y sobre artes visuales en general, derivó en los años sesenta hacia la semiótica y la teoría de la comunicación. Estas disciplinas le llevan a pensar en la imagen (sonora y visual) en tanto que enmarcada en un sistema de signos; imágenes que son resultado de una transposición cinemática del lenguaje oral o del arte verbal.

\section{NOTAS}

1 Originariamente publicado con el título "Úpadek filmu?" en Listy pro Umění a Kritiku (Cuadernos de Arte y Crítica, 1, 1933). A partir de aquí se citará entre paréntesis la página de la traducción española (Jakobson, 1976b, 173-82), en realidad una retraducción hecha a partir de la versión francesa. Nos apoyamos asimismo en la traducción de Elena Sokol, revisada por el autor para su publicación en inglés (Jakobson, 1976c). El artículo original en checo no incorpora notas, aunque sí la traducción inglesa.

2 "Lo escribí después de haber trabajado yo mismo para el cine (...) El artículo no se escribió inicialmente para la revista en la que apareció. Lo hice porque [Vladislav] Vančura quería publicar un volumen de artículos sobre cine, volumen que por el motivo que fuera nunca se llevó a cabo. Como ya había escrito el artículo, entonces pensé en darlo a la revista" (Jakobson, 1967, 161 y 162). Efectivamente, una nota a pie de artículo
Recibido: 17 de octubre de 2008
Aceptado: 20 de marzo de 2009

doi: 10.3989/arbor.2011.748n2019 
original avisa del libro en preparación Premisas del cine checo.

3. Si se lee el párrafo, se advertirá su sentido completo: "A mi juicio, la música en el cine no tiene otro objetivo que el de ocupar los oídos mientras que toda la atención se concentra en la visión, e impedirles oír el silencio exasperante que harian el ruido del proyector y los movimientos del público. Importa pues que no llame la atención por su riqueza o su novedad, ni que desvíe el seguimiento del espectáculo" (Martin, 1925, 116).

4. En realidad este aserto de Louis Delluc no corresponde a Photogénie -tal y como indica Jakobson en una nota-, sino a la crítica "D'Oreste à Rio Jim", aparecido en la revista $\mathrm{Ci}$ néa en 1921 (Delluc, 1985, 138).

5. Epstein escribe al respecto: "Entonces el cisma del teatro filmado. El teatro filmado no era eso. Incluso era lo contrario. Aún a este arte, entonces tan nuevo que sólo existía como un presentimiento, le faltan las palabras, incluso hoy, por haber servido demasiado a imágenes lamentablemente no olvidadas" (Epstein, 1921, 29).

6. El término siuzhet es usado por los formalistas rusos para definir la estructura narrativa de la obra literaria. También se aplica a los aspectos técnicos de la realización de películas como pueda ser el montaje. Opuesto a la siuzhet está la fábula, que da cuenta del curso de los acontecimientos, de la historia.

7. Jakobson remite a la edición original de El arte cinematográfico y el montaje del filme: ensayo de introducción a la teoría y estética del cine (Leningrado, 1926). El libro de Timoshenko se tradujo parcialmente al alemán en Vsevolod Pudovkin, Filmregie und Filmmanuskript (Berlín, 1928). Hay edición en castellano (Pudovkin, 1956), pero la parte dedicada a los intertítulos no figura en esta traducción.

8. En esta dirección también puede leerse: "Sería extremadamente interesante hacer una comparación entre Chaplin y los hermanos Marx, como dos etapas del burlesco, dos etapas del cine cómico. Yo repito a menudo que, si fuera más joven, intentaria escribir una monografía sobre el tema" (Jakobson, 1967, 157).

\section{BIBLIOGRAFÍA}

Albèra, François (1998): Los formalistas rusos y el cine, Barcelona, Paidós.

Balázs, Béla (1926): Der Sichtbare Mensch: Eine Filmdramaturgie, Halle-Salle, Wilhelm Knapp.

Beucler, André (1925): "Le poème cinématographique", Les Cahiers du Mois, 1617, 1925, pp. 133-35.

Delluc, Louis (1985): Écrits cinématographiques, vol. I, Paris, Cinémathèque Française.

Eisenstein, S. M. (1986): La forma del cine, México, Siglo Veintiuno.

- (2001): Hacia una teoría del montaje, vol. I, Barcelona, Paidós.

Epstein, Jean (1921): Bonjour cinéma, París, La Sirène.

Jakobson, Roman (1967): "Conversazione sul cinema", Cinema e Film, I, 2, pp. 157-62.

- (1973): Fundamentos del lenguaje, Madrid, Ayuso.

- (1975): Ensayos de lingüística general, Barcelona, Ariel.

- (1976a): Nuevos ensayos de lingüistica general, México, Siglo Veintiuno.
- (1976b): "¿Decadencia en el cine?", en Urrutia, Jorge, ed., Contribuciones al análisis semiológico del film, Valencia, Fernando Torres, pp. 173-82.

- $\quad$ (1976c): "Is the Cinema in Decline?", en Semiotics of Art: Prague School Contributions, Cambridge, MIT Press, pp. 145-52.

- (1981): Lingüistica, poética, tiempo: conversaciones con Krystina Pomorska, Barcelona, Crítica.

- (1987): Language in Literature, Cambridge, Harvard UP.

Kuleshov, Lev (1974): Kuleshov on Film, Berkeley, University of California Press.

Martin, Frank (1925): "Musique et cinéma", Les Cahiers du Mois, 16-17, pp. 11619.

Moussinac, Léon (1967): L'âge ingrat du cinema, Paris, EFR.

Mukařovský, Jan (1977): Escritos de estética y semiótica del arte, Barcelona, Gustavo Gili, 1977.

Pudovkin, Vsevolod (1956): Argumento y montaje: bases de un film, Buenos Aires, Futuro.

Ramain, Paul (1925): "L'influence du cinéma sur la musique", Les Cahiers $d u$ Mois, 16-17, pp. 120-26.

Sklovski, Viktor (1971): Cine y lenguaje, Barcelona, Anagrama.

Taylor, Richard y Christie, lan, eds. (1988): The Film Factory, Londres, Routledge and Kegan Paul.

Teige, Karel (2002): Film, Madrid, Semana de Cine Experimental de Madrid.

Toman, Jindrich (1995): The Magic of a Common Language, Cambridge, MIT Press.

Tupitsyn, Margarita (2003): Malevich y el cine, Barcelona, Fundación La Caixa.

Vuillermoz, Émile (1927): "La musique des images", L'art cinématographique, vol. III, París, Félix Alcan, pp. 39-66. 